\title{
Advances in Propagation Techniques of Pomegranate
}

\author{
Y. D. Pawar ${ }^{1 *}$ and Pushpraj Singh ${ }^{2}$ \\ ${ }^{1}$ Krushi Vigyan Kendra, S. D. Agricultural University, Deesa, (Gujarat) India-385 535 \\ ${ }^{2}$ Krushi Vigyan Kendra, S. D. Agricultural University, Tharad (Gujarat) India
}

*Corresponding author

\begin{abstract}
A B S T R A C T
Pomegranate can be propagated by seed, air layering, grafting, shoot cuttings and tissue culture. Seed propagation is used to raise the rootstocks that can be utilized for germplasm conservation and rootstocks breeding purpose. Vegetative propagation methods are used to multiply selected genotypes that bring similar character in form of clones having similar characters to mother plant. Vegetative propagation techniques (hard wood cutting, layering) are practices to raise the saplings for commercial production in pomegranate, because it perpetuates all characteristics of each cultivar. There are various propagation techniques are available, and the refinement of those techniques are also been done in large. However, recent time the suitable propagation method especially grafting and tissue culture techniques could be useful to utilise the resistant root stocks and multiply resistant in the sapling. Although there is diversity in propagation methods and new technologies are also being experimented. Moreover, obtaining healthy and quality seedlings is still one of the main constants for commercial pomegranate growers. Use of resistant cultivars and pathogen-free substrates should be prioritized due to susceptibility of pomegranate to wilt and nematodes. Therefore, the aim of this review is to gather the data referring to advances in researchin different propagation methods that can be used to propagate pomegranate and summarize the progress obtained in recent years.
\end{abstract}

Keywords

Propagation, pomegranate, cuttings, layering, medium, IBA

\section{Article Info}

Accepted:

18 May 2020

Available Online:

10 June 2020

\section{Introduction}

Pomegranate (Punica granatum L.) belongs to the family Punicaceae, which comprises only one genus Punica and two species; $P$. granatum and $P$. protopunica. Pomegranate is one of the favorite table fruit. It is an economically and nutritionally important species of the tropical and subtropical regions of the world due to its delicious edible fruits and pharmaceutical and ornamental usage.
Pomegranate is considered native to Iran. It has been widely cultivated throughout drier parts of Southeast Asia, Malaysia, the East Indies tropical Africa and India.

In India, it is found from Kanyakumari to Kashmir but is cultivated in Maharashtra, Karnataka, Gujarat, Rajasthan, Tamil Nadu, Andhra Pradesh, Uttar Pradesh, Punjab and Haryana. The fruit juice is a good source of sugars, water, vitamin $\mathrm{B}$, vitamin $\mathrm{C}$, 
pantothenic acid, potassium, antioxidant polyphenols and a fair source of iron. Some parts of the pomegranate tree (leaves, immature fruits, fruit rind and flower buds) have been used traditionally for their medicinal properties and also for tanning of leather. Wild pomegranate is too acidic and of little value except as souring agent (Anardana). The double-flowered pomegranates (which do not bear fruits) are grown in parks and ornamental gardens for their beautiful red flowers.

India is the largest producer of pomegranate in the world. In India, the total area under pomegranate cultivation is about 209 thousand hectares area with a total production 2442 thousand MT and productivity $6.91 \mathrm{t} / \mathrm{ha}$ (Anon, 2017). Among the states, pomegranate is grown in Maharashtra, Karnataka, Gujarat, Andhra Pradesh, Uttar Pradesh, Haryana, Jharkhand, Himachal Pradesh, Madhya Pradesh, Jammu \& Kashmir, Punjab, and West Bengal. In Gujarat, it is cultivated 18.54 thousand hectares area with a total production 278.10 thousand MT and productivity $11 \mathrm{t} / \mathrm{ha}$. The pomegranate is propagated by seed but seedlings are unsatisfactory. Seeded plant produces uneven size of fruits and low yields. Cutting and layering are the major adopted practices in pomegranate propagation.

Due to diversified and adverse adoptive nature of the pomegranate. It is grown in almost all part of the India. Since decades pomegranate fruit has gained popularity among the growers due to its higher profitability. In addition to its adaptability, fruits have good nutritional charters and having medicinal properties in all part (seed, rind and peel) the fruit which is used in pharmaceutical and processing industry. Due to deadly diseases like wilt and nematode which are emerged as a major threat to pomegranate plantation in many arid and semi arid region of India. Since last 4-5 year the planting area has also decrees. Currently, cutting and layering method are the mostly used for pomegranate propagation. However, tissue culture technique is also gaining popularity recently. But due to the limited infrastructure and unawareness of the grower having less utilization and also this is not a cost effective technique. Per plant cost is more compare to cutting and layering. To overcome these obstacles, the production of quality seedlings is the first step to obtaining productive and healthy orchards.

Plant propagation is multiplication of plants by both sexual and asexual means. Conventionally pomegranate plant can be propagated through seed but seed propagation is not utilized for commercial plant material generation due to the constants i.e. variability, precocity and undesirable plant stand etc (Sonawane, 2017). Therefore, vegetative propagation is the only way to generate pomegranate plants for commercial uses. There are various vegetative methods are demonstrated in pomegranate i.e. cutting and layering. Among the available vegetative methods of propagation, cuttings are universally used for raising pomegranate plants on commercial basis. Since decades several advance experiments on pomegranate propagation technology has been conducted and few techniques are also developed which could be very useful for the farmers and researcher to further research on pomegranate propagation. The main objective of this article to summarizes recent advances in existing propagation technique and also detailing the recent developed propagation techniques in pomegranate.

\section{Sexual propagation}

Sexual reproduction is the union of the pollen and egg, drawing from the genes of two parents to create a new, third individual. 
Sexual propagation involves the floral parts of a plant. Asexual propagation involves taking a part of one parent plant and causing it to regenerate itself into a new plant. The resulting new plant is genetically identical its parent.

Asexual propagation involves the vegetative parts of a plant: stems, roots, or leaves.Seed propagation is an easy and economical method of pomegranate propagation but the seedlings are unsatisfactory. Seeded plant produces uneven size of fruits and low yields. Commercially, seed propagation in pomegranate is only used for genetic improvement, production of disease-free plants and cryopreservation of valuable germplasm (Taheri et al., 2014).

The seeds of pomegranate germinate very fast even if sprinkled on the top of the soil but the seed usually have little problem with dormancy. The dormancy of pomegranate seed can be break by submersion in $\mathrm{H}_{2} \mathrm{SO}_{4}$ for $15 \mathrm{~min}$ and cold stratification under greenhouse for 60 days has increased germination percent of pomegranate seed (Olmezet et al., 2007).

Seed treatment with acid for 30 min was also improved germination percent and growth of pomegranate plant (Materechera and Seeiso, 2013). Efficient germination and growth of germinated seedling of pomegranate was also found effective in the treatment using Soaking of pomegranate seeds in distilled water (hydropriming) in the dark for $24-48 \mathrm{hrs}$ at $25{ }^{\circ} \mathrm{C}$ with application of $1-3 \% \mathrm{KNO}$.

\section{Vegetative propagation}

Cutting and layering are the major adopted practices in pomegranate propagation since ages there are several researchers has reported advances in these techniques in terms of size of cutting age of cutting, time of layering practices, media for rooting in cutting and layering etc.

\section{Stem cuttings}

Stem cutting is an old and easiest method for pomegranate propagation. Generally 15-20 $\mathrm{cm}$ length of shoots with pencil size thickness is most practicing by the nursery man. But the capability of rooting, sprouting percentage varies from cultivar to cultivar, location to location, season to season and age of the mother plant shoots (Singh et al., 2017). There has been several experiment carried out by various researchers to optimized the size of cutting, season of propagation, types and amount of growth regulators etc. to make the pomegranate propagation more advances and reliable for commercial pomegranate growers.

\section{Types of cutting and season of planting}

Season of planting and types of cutting plays great role in success of cuttings. Time of shoot selection for cutting is a crucial operation for cutting, the performance of cutting on rooting and shooting is depend upon the physiological potential of the cuttings (Chandra and Babu, 2010).Various researchers have found significant influences of cutting season and age of shoot for cutting. (Navjot and Kahlon, 2007). Observed maximum 90.12 percent sprouting in January month planting and the minimum 79.83 percent in July plantings. However, (Saroj et al., 2008).Revealed that July month is a best time for planting of cutting under mist system by using both semihardwood and hardwood cuttings after treating with 2,500 ppm IBA. Cutting planted during $30^{\text {th }}$ January was recorded highest percent of sprouting, plant height, shoot length $(\mathrm{cm})$, number of shoots and shoot girth in pomegranate (Kour, 2009). However, Singh et al., 2011) found best sprouting during December planting.

In case of cutting types maximum sprouting 88.68 percent was found in the middle portion 
of shots used for cutting and the minimum 82.04 percent from the sub-apical type of cuttings. The cuttings taken from hardwood stems had higher rooting percentage than those taken from semi-hardwood stems (Owais, 2010). The cutting planted between 15 December - 15 January month using Growth regulator (IBA) applied by quick dip for 5 second recorded positive effect on sprouting percentage of cutting (Singh et al., 2011). Whereas, (Purohit and Shekharappa, 1985) found better response on sprouting percent from the shoots taken form basal portion of the mother plant in the month of January compare to the cuttings taken from any other portion of the shoot. Suitability of January month for pomegranate cutting emphasized by various workers that might be due to the higher accumulation of carbohydrates in January plantings as it succeeded dormant season and soon followed by a congenial climatic conditions for sprouting of the buds (Navjot and Kahlon 2007).In some cases low sprouting of buds in July planting might have due to higher temperature that adversely affected the sprouting of the buds. These variations may also occur due to species or locality differences (Singh, 2017).

In case of age of shoots middle portion of shoots reported better on sprouting percentage, plant height and survival of sprouts, that might be due the cuttings from the middle portion have higher levels of carbohydrates than the sub apical cuttings. The basal portion accumulate higher concentration of carbohydrate than the middle portion of shoots but the sprouting of cutting form basal portion is reported less that might be due to the age and over maturity of the wood.(Mehta et al., 2018). Concluded the effect of IBA Concentration and time of planting on rooting in pomegranate (Punica granatum) Cuttings. They have tested three different planting times $\left(25^{\text {th }}\right.$ December, $10^{\text {th }}$ January and $25^{\text {th }}$ January) of cutting and treated with (500 ppm, 1000 ppm) IBA. Results showed that highest number of sprouted cuttings (7.11), number of sprouts per cutting (4.00), number of leaves on new shoots (10.89), and percentage of rooted cuttings $(71.11 \%)$ was recorded under January $25^{\text {th }}$ planting.

\section{Size of cutting}

Cutting (length and diameter) are the outmost important for success of cutting. Mortality of cutting is a major constraint (Sharma et al., 2009). Generally, 6-12 $\mathrm{mm}$ or pencil thickness, average $10-20 \mathrm{~cm}$ long with three or four buds thick stem cuttings provide optimum rooting (Rajan and Markose, 2007).The influence of cutting size on rooting has much clear, but the storage of carbohydrate in the shoot might be influence the rooting and shooting process in the cutting. (Tripathi, et al., 2004).Found better rooting and sprouting in hard wood cutting with $20-25 \mathrm{~cm}$ long cutting and $1.0 \mathrm{~cm}$ diameter of dholka and khandhar cultivars. (Kahramanoglu and Umar, 2018).

Determined the effects of cutting length, collection time of cuttings and rooting media on the sprouting of dormant semihard wood cuttings of Wonderful cultivar. The cutting lengths $(10,20,30$ and 40) $\mathrm{cm}$ was collected during February to march. The highest sprouting percentage was $98 \%$, from $10 \mathrm{~cm}$ cuttings length, collected $43 \pm 3$ days before sprouting (DBS) grown in perlite. The results of his experiment also reviled that the sprouting percentage is higher at the shorter cuttings. As time pass, the sprouting percentage of the cuttings decrease, and is important to collect cuttings about 40 days before sprouting. About $15-20 \mathrm{~cm}$ long hard wood cuttings, $0.5-1.0 \mathrm{~cm}$ diameter and having three to four buds were separated from the healthy trees and planted in mid-January (Rajkumar et al., 2017). 


\section{Effect of growth regulators on rooting and} sprouting

Rooting in the vegetative propagation method like cutting is a major constraint. Root and shoot inanition is foremost important phenomena in vegetative propagation. To initiate the roots and shoots in vegetative propagation growth regulators play important role. Using of growth regulators for root and shoot initiation is an old practice. Application of exogenous auxin is required to achieve rooting (Diaz-Sala et al., 1996; Blazkova et al., 1997).Among phytohormones, auxin plays an essential role in regulating roots development and it has been shown to be intimately involved in the process of adventitious rooting (Tiberia et al., 2011). Application of plant growth regulators may be an effective technique for increasing the rooting ability and the growth of vegetative fragments cuttings (Elena et al., 2012).

Auxin enters into the cutting portion mostly via the cut surface (Kenney et al., 1969) and promotes adventurous root initiation. IBA is one of the most utilized and efficient auxin types that promote roots in the cutting fallowed by IAA and NAA. The concentration of IBA for rot initiation is varies on types of cutting, time of cutting and other material used for rooting. Cutting length, diameter, and the interaction between cutting length and diameter significantly affects rooting efficiency (OuYang et al., 2015).Various experiments are reported in recent times to determine the concentration of IBA and other growth regulator with respect to time and types of shoot cutting used. (Ram et al., 2005). Recorded minimum days for sprouting and maximum number of sprouts per cutting with IBA (5000 ppm) + PHB $(1500 \mathrm{ppm})$ in Kandhari variety of pomegranate. IBA $500 \mathrm{ppm}+$ Borax $1 \%$ (for 15 minutes) treatment was best for both (semi hard wood and hard wood cuttings)to promote highest rooting percentage and root length
(Sharma et al., 2009). Whereas, (Owais, 2010). Found interactive effect of hard wood cutting with IBA $9000 \mathrm{ppm}$ in Hmadee Hmaree cultivar. The cuttings treated with IBA $100 \mathrm{ppm}$ (slow dip) and $2000 \mathrm{ppm}$ (quick dip) planted in the month of January exerted positive effect with regard to sprouting percentage (Singh et al., 2011). Use of IBA $2500 \mathrm{ppm}$ in Hardwood cuttings planted in soil + cocopeat as a rooting media recorded maximum shoot growth in respect to length and number of sprout, root number, sprouting percentage (Saroj et al., 2008; Shinde, 2012) However, (Padma, 2014).Reveled the combination of Indole Butyric Acid (IBA) and Naphthalene Acetic Acid (NAA) @ 200ppm each gave highest percentage of cuttings rooted, highest number of roots per cutting, longest roots, and least number of days to root. Whereas, the other combination (IBA 300ppm +NAA 300ppm) resulted less number of days taken for root initiation and percentage of cuttings rooted, except for the observations on various stem leaf characters and all other. But differs significantly over control with respect to days taken for root initiation, percentage of cuttings rooted, per cent success after 30 days, 45 days and 60 days, number of roots in cutting, length of longest root and various stem and leaf characters than the control (Kabir et al., 2017).

Experiments showed that the cuttings of pomegranate was better in rooting and shooting with the treatment of $0.2 \%$ IBA followed by $0.4 \%$ IBA. Highest rooting percentage $(70 \%)$ and longest root length $(11.75 \mathrm{~cm})$ was found with $0.2 \%$ IBA followed by $0.4 \%$ IBA $(47.5 \%$ and $7.95 \mathrm{~cm}$ respectively).

However, highest root number (32) and maximum root diameter $(2.7 \mathrm{~mm})$ were recorded with $0.4 \%$ IBA followed by $0.8 \%$ IBA (28 and $2.47 \mathrm{~mm}$ ) respectively. (Mehta $e t$ al., 2018). Found best results on highest 
number of sprouted cuttings (7.33), number of sprouts per cutting (4.66), length of longest sprout $(7.28 \mathrm{~cm})$, number of leaves on new shoots (10.66) and percentage of rooted cuttings $(73.33 \%)$ with the application of 500ppm IBA. (Abdul et al., 2018). Studies on the influence of bio-fertilizers and auxin on growth and rooting in cutting of Bhagwa and Ruby cultivars of pomegranate The results revealed that the application of IBA 1500 ppm + NAA 1500 ppm + Biomix resulted early sprouting of cuttings (8.60 and 7.80 days), number of cutting sprouted (18.33 and 17.67), length of longest shoot (39.73 and $41.53 \mathrm{~cm}$ ), in both the cvs. Bhagwa and Ruby, respectively.

\section{Use of bio inoculums for rooting}

Better rooting is a prime concern of vegetative propagation. In order to improve the rooting ability and success per cent techniques have been improvedby the use of synthetic root promoting growth regulator and biofertilizers (Damar et al., 2014).The use bio-inoculums i.e. PSB, Rhizobium Azotobactor, are been use in large scale to increase the nutrient efficacy and maintaining soil health in the field. Similarly the microorganisms i.e. Trichoderma are plant growth promoting bacteria (PGPR), which can stimulate the growth and development of agricultural crops due to their activity as biofertilizers (Glick, 2012). This is also help in promoting root and increasing the physiological activity of cutting. (Kumar et al., 2001). Reported the Inoculation of cutting with Trichderma harzianum was effective in efficient rooting and survival percent of rooted shoots in variety RCR-1 (Barde et al., 2010). Reported that IBA at 2000 ppm gave maximum number of shoot per cutting (2.80), with combination of PSB. Similarly, (Damar, 2014) also found the combination of PSB and 2000 ppm IBA was best for maximum rooting, growth and success of pomegranate cuttings followed by combination of Azotobacter and $2000 \mathrm{ppm}$ IBA. However, (Hakim et al., 2018). Reported treatment IBA 1500 ppm + NAA 1500 ppm + PSB + PGPR, further they have reported that combination of treatment with biofertilizers have impacted on total chlorophyll content of leaves (2.36 and $2.62 \mathrm{mg} / \mathrm{g}$ ), and leaf area (33.54 and 34.35 $\mathrm{cm} 2$ ) in cvs. Ruby and Bhagwa respectively, recorded in control.

\section{Growing media for raising cutting}

The growing medium plays an important role in the successful propagation. Selection of suitable growing medium is a prime concerns that needed to be a successful rooting and shooting form cutting. A good rooting medium should hold the cuttings in place during rooting period, provide moisture, permit exchange and provide appropriate light penetration (Eed et al., 2015). The choice of growing medium is depends on availability, production cost, suitability the planting material. (Ansari, 2013). Examined the Interaction between collecting time of cuttings and media on rooting characteristics of pomegranate cultivar Malas torsh. He Studied the influence of seven collecting times (Nov-Feb) with fifteen days interval using different rooting media (Perlite, cocopeat, vermiculite, sand and equal mixes). The Result of his experiment reviled significant effects of cutting time and media used for planting on rooting characteristics. The most effect on rooting percentage and root numbers was obtained on cutting collected on 5 Jan and 4 Feb in planted in vermiculite fallowed by 19 Feb in vermiculite + sand. In another experiment (Tanuja et al., 2017) found best result on high rooting percentage in hardwood cuttings with vermiculite rotting medium $(76.67 \%)$, while the lowest percentage was obtained under soil (26.67\%.). The maximum number of primary roots was noticed in vermiculite $(36.33 \%)$ and 
the lowest in soil (16.67\%), which showed significant difference (Rajkumar et al., 2019). Identified the most efficient growing medium for root and shoot development in stem cuttings. The cutting was treated with 2500 ppm of IBA (3- Indole butyric acid) using quick dip technique (for 5 seconds) and planted in five rooting substrates i.e. sand, vermiculite, perlite, cocopeat and garden soil (control) alone and in combination at 1:1 $(\mathrm{v} / \mathrm{v})$. They found the better response of Perlite + vermiculite $1: 1(\mathrm{v} / \mathrm{v})$ and vermiculite + cocopeat in terms of rooting percent (82.33), number of roots per cutting (32.67), fresh and dry weight of roots (0.61 and 2.08 )mg shoots per cutting (80.33) and survival (76.0 per cent) and it may be the appropriate alternatives for the better rooting and establishment of pomegranate cultivar Phule Arakta. Further, (Ghani, et al., 2019).Revealed the use of sand + soil+ FYM $(1: 1: 1)$ a plating medium for cutting was found to be the best suitable media for Phule Bhagwa Super cultivar of pomegranate.

\section{Air layering}

Layering is anold technique use to propagate many woody plants. It is form of rooting cuttings where adventitious roots are produced while the stem is still attached to the mother plant. The rooted part of shoots is detached from mother plants after it is rooted well. This is a simple method of propagation in pomegranate. Air-layering is one of the most successful and adopted methods of pomegranate propagation (Madhuri,2017). The layered shoots reproduce plants with better rooting than cuttings (Tomar, 2011).Air layering can be advantageously useful in pomegranate propagation to minimize the time for fruiting earlier than cutting planting to increase the success percentage (Tayade, et al., 2018). In layering rooting percentage and survival of layer plant is depends on the types of rooting medium, concentration of growth regulators and the age of mother plant shoot. In the recent past various refinements have been done on these aspects to make layering technique more commercial and economical efficient. (Tomar, 2011). Found better rooting percent in the air layering using sandy clay soil as medium incorporated with IBA 2000 ppm. (Patel, et al., 2012). Also recorded better results on more number of roots, high survival percentage in sphagnum moss with IBA $5000 \mathrm{ppm}$ in cultivar G-137. This treatment also gave early root initiation in 16.79 days. Maximum numbers of secondary roots 34.43 , root length $11.29 \mathrm{~cm}$, fresh root weight 0.55 and maximum dry root weight 0.28 followed by cvs. Bhagva and Mridula. (Madhuri,2017). Found maximum success of air layering and better rooting during rainy season by using lanolin paste as a rooting medium enriched with 1000 ppm IBA at the upper side of the ring and covered with moist moss grass and white polythene. The layered shoots were separated after 30-90 days.

\section{Rooting medium for air layering}

The rooting media enriched with suitable growth regulator played major role in root initiation. Earlier, Soil, Sand and FYM alone or with proportion $(2: 1 ; 1,1 ; 1 ; 1)$ were major in use for root initiation and had effective results too (Jain\& Parmar 1993; Hore\& Sen 1994). But the efficacy of medium was poor in term of water holding capacity and utilization of PGRs. Further the advancement in rooting media has come with the use of sphagnum moss, coco peat and saw dust those have higher moisture holding capacity with lighter weight, which enhance root formation.(Bhosale et.al., 2009).Sphagnum moss with IBA 5000 ppm was best combination giving the best rooting, survival and was economical also. The air layers made with sphagnum moss + IBA 5000ppm showed early root initiation (17.33 days) and also recorded minimum number of days (25.66 
days) followed by coco peat + IBA 5000ppm. The treatment combination sphagnum moss + IBA 5000ppm significantly influenced root length and fresh, dry weight of root and showed maximum root length $(7.5 \mathrm{~cm})$, fresh root weight $(0.74 \mathrm{~g})$ and dry root weight $(0.29$ g). After 45 days the maximum survival percentage of air layers in the nursery bed $(73.33 \%)$ and in poly bag $(100 \%)$ was observed in air layering with sphagnum moss + IBA 5000ppm (Melgarejo et al., 2000). Studied the rooting capacity of eleven pomegranate (Punica granatum L.) clones, using plastic to cover the soil and concluded that clones ME 12, CRO 2 and PTO 8 with $12,000 \mathrm{ppm}$ IBA+wounds+plastic cover treatment recorded highest rooting percentage.

\section{Mound layering}

Mound layering is quite new practice of pomegranate propagation which isstill been experimented and evaluated by the researchers for it refinement. (Singh, et al., 2017).The experiment was conducted to elucidate the effects of different spacing on regeneration of stool shoots in pomegranate (Punica granatum L.).

The results of their experiment revealed that the performances of stool shoots were significantly influenced by spacing between mother stocks. They recorded the total shoot production per plot and per $\mathrm{m}^{2}(217.25$ and 36.37 , respectively) and rooted shoot production per plot and per $\mathrm{m}^{2}(117.15$ and 19.51, respectively) were found significantly higher at the spacing of $0.5 \times 0.5 \mathrm{~m}$. The rooting of stool shoots found increased from 55.50 to $70.95 \%$ with the increase in spacing from $0.5 \times 0.5 \mathrm{~m}$ to $1 \times 1 \mathrm{~m}$.

\section{Grafting}

Grafting technique is a quite recent approach to propagate pomegranate. Available technique (layering and cuttings) are efficient to produce sapling in large scale, but these techniques have some limitations. These techniques are not useful in cope up with biotic and a biotic stress. Currently wilt is an emerging threat to the pomegranate industry (Chandra and Jadav, 2012).Infection of nematode is another emerging threat for pomegranate growers moreover, in spite of that several biotic (Bacterial leaf spot disease, wilt aspergillums fruit rots etc) and abiotic (creaking, sun burning etc) factors are affecting pomegranate crops.

Appropriate potentiality of specific germplasam can be utilized by using root stocks. An efficient Grafting technique by using tolerant rootstock could be useful to overcome with these threats.Various researches has took great initiatives on determines the suitable grafting methods and time of grafting. M. (Vazifeshenas et al., 2009), Tested the effects scion-rootstock combination on growth, tree size, yield and fruit quality of some Iranian pomegranate cultivars. 'Zagh', 'Shavar' and 'Malas Esfahani' as scion grafted on 2 years old clonally propagated root stocks 'Golnar Farsi', 'Torsh Ma' moly Zabol','YekKilloy HoshakSaravan', 'PoostSyah', 'KhafriPoost SefidJahrom', 'Zagh', 'Shavar' and 'Malas Esfahani' having similar height and diameter. They found the significant effect of rootstock on scion cultivar on tree size, vigour and yield. Grafting plant gave higher yield than the own-rooted plants, but grafted trees showed lower vigour and tree size compared with ungrafted plant. Root stock 'Torsh Ma' moly Zabol' led to the lowest tree size and height, and the lowest rate of sunburn scald disorder. Whereas, Golnar Farsi' rootstock in spite of higher yield produces also produced lowest suckers. Identification of such root stock using grafting technique can maximised the pomegranate yield.(Chandra et al., 
2011).Reported success of wedge grafting done on $30 \mathrm{Jan}$. in pomegranate cv. Bhagwa. Significantly highest graft success found at 90 Days after grafting.In recent two grafting methods (wedge and tongue grafting) are experimented in the large way with the time of grafting. Further they also achieved significantly higher scion sprouting $(96.67 \%)$ in One-year-old seedlings of pomegranate cv 'Phule Arakta' after 21 days of wedge grafting done in the last week of January.

Consequently maximum graft success $(85.00 \%)$ was recorded after 90 days of grafting with wedge grafting done on 30 January. Plant height and scion length after 6 months of grafting was higher when wedge grafting was done between 30 December and 30 January. Grafted plants during this period had perfect union as indicated by normal diameter recorded at graft union.(Karimi and Farahmand, 2011)was investigated bench grafting in pomegranate on Gorj-e-Dadashi (S1) and Gorj-e-Shahvar (S2) variety using $\mathrm{R} 1, \mathrm{R} 2$ and R3 rootstocks. bud take percentage (BT), bud take stem length, internodes length and shoot fresh and dry weight were influenced by the rootstocks. The highest bud take was obtained in rootstock R3 on Gorj-e-Dadashi scion. The lowest bud take was observed in rootstock R3 on Gorj-eShahvar variety.Maximum root fresh weight, shoot fresh weight, shoot length was recorded in variety GoolSafid-e-Ashk-e-Zarwhile highest bud take was recorded with variety Gorj-e-Dadashi. The application of $500 \mathrm{ppm}$ IBA recorded highest growth parameters in pomegranate rootstocks. The interaction of rootstock/scion showed that the highest successful callus formation at graft union was obtained in R2S1 (Mehrdad et al., 2016). Studied the effect of rootstock, scion using Cleft grafting of Rabab-e-Neyris and Khafr-eJahromcultivar as scion on Poust Ghermez-eAli Aghaei, Garch-e-Dadashi and Garch-eShavarrootstocks. Parameters were recorded on: 60,120 and 180 days after grafting.

The highest rate of vegetative parameters was at 180 days after grafting. They observed that the Cleft grafting technique showed to be more successful method for propagation and had significant effect on grafting success and establishment of grafted seedling. But rootstock and scion genotypes did not show any significant effect on grafting success and survival of grafted plants. However, there was negative correlation between phenolic compounds of rootstock and scion with the percent of survived grafted seedling.(Ranpise and Ahire, 2016).Assessed eleven rootstocks viz., Ganesh (R1), Bedana Suri (R2), Alandi (R3), Kandhari (R4), Jallore Seedless (R5), Jodhpur Red(R6), Patna-5 (R7), Muscat (R8), Yercaud (R9), BedanaSedana (R10) and Daru (R11) of pomegranate using two propagation method Wedge grafting (M1) and Patch budding (M2) on cv. Phule Bhagwa Super.

The 6-9 months old cv. Phule Bhagwa Super having $15 \mathrm{~cm}$ long leafless shoots grafting/budding on one year old seedlings of different rootstocks (Ahire et al., 2017). Assessed the graft compatibility of various rootstocks with cv. Phule Bhagwa Super by adapting Wedge grafting and patch budding. Rootstock Bedana Suri and Alandi took the minimum time for bud sprout (17.77 days). The highest bud sprout $(80.00 \%)$ at 30 days after grafting (DAG)/ days after budding (DAB) was recorded in Bedana Suri. The maximum per cent survival $(76.67 \%)$ of grafts/buds at 90 DAG/ DAB was recorded in Bedana Suri. The highest shoot growth rate was registered on Bedana Suri rootstock. Whereas, maximum girth at graft/bud union was recorded in Bedana Suri. The highest stock/scion girth ratio (1.00) was recorded in the rootstocks, Ganesh, Bedana Suri and Kandhari with wedge grafting. Bedana Suri rootstock produced longer shoot and root and also highest fresh shoot and root weight. The 
highest shoot/root weight ratio was recorded in Kandhari (Karimi et al., 2019). Studied the effects of three root stocks Gorj-e-Dadashi', 'Gorj-e-Shahvar', and 'Post Ghermaz-eAliaghai'; on 'Rabab-e-Neyriz' and Khafr-eJahroom'; two pomegranate cultivars as scion. The lowest current-year shoot length and diameter of the shoot were obtained with 'Gorj-e-Dadashi' rootstock, where as in 'Rabab-e-Neyriz'cultivar it was obtained with 'Post Ghermaz-e-Aliaghai'. The results showed that the highest chlorophyll a concentration, total chlorophyll, shoot diameter and leaf area were obtained when 'Rabab-e-Neyriz' grafted on to 'Gorj-eShahvar'. The lowest sucker number, sucker length, sucker fresh, and dry weight were obtained when 'Rabab-e-Neyriz'cultivar grafted on to 'Post Ghermaz-e-Aliaghai'.

The rootstock type affected on graft success percentage.Success of grafting is depend upon the compatibly of rootstock and scion (Karimi and Farahmand, 2011).The compatibility could be due to the morphological, Physiological variations among stocks and scion (Karimi and Nowrozy, 2017). Found positive correlation between soluble sugar rate of scion with graft success percentage whereas the phenol compounds of rootstock had negative correlation with mortality percentage in Ranab-e- Neyriz' root stock grafted on to 'Gorj-e-Shahvar' cv. of pomegranate. The grafting is new approach, where the more concern has to be given on graft success sprouting percents root stock and scion compatibility. Moreover performance of grafted plants also needs to be evaluating in large scale under field condition then only the method can be recommended for large scale sapling production.

\section{Micropropagation}

Micropropagation is a regeneration of whole plant through tissue culture where a callus mass has been initiated from a single explant, and within a very short time, a large number of plantlets can be produced from a callus tissue in vessels with defined culture medium and under controlled environmental conditions (Bhatia and Sharma, 2015).The process of micro propagation involves 5 distinct stages 1) Identification of elite mother plants/parental material. 2) Selection of suitable explants, their sterilization and transfer to nutrient medium for establishment / initiation of a sterile culture explant (Rajkumar et al., 2017). Now a day's plant tissue cultured plants has large demand by the pomegranate growers due to its ability of disease and pest resistant and precocity in bearing. Since decades various researches has been done on development of efficient protocol to regenerate pomegranate plant in vitro. (Naik et al., 1999).has reported efficient protocol for in vitro propagation of pomegranate. cv. Ganesh using nodal stem segments of a mature tree (Murkute et al., 2004). Regenerated pomegranate plant by using nodal segment explants in the MS basal medium supplemented with BAP $1.0 \mathrm{mg} \mathrm{l-1+}$ NAA $0.5 \mathrm{mg} \mathrm{1-1.}$

The elongated and proliferated shoots were rooted on half-strength MS basal medium supplemented with $0.5 \mathrm{mg} \mathrm{1-1}$ either NAA or IAA and plant were hardened on vermi compost + soil mix (1:1) in mist chamber with 50\% survival. (Singh et al., 2013). Observed maximum percentage establishment of cotyledonary node explants on Murashige and Skoog (MS) medium + $1.0 \mathrm{mg} / \mathrm{l} \mathrm{6-}$ benzylaminopurine (BAP) $+0.5 \mathrm{mg} / \mathrm{l}$ naphthalene acetic acid (NAA). The maximum frequency of multiple shoots in cotyledonary explants $(86.33 \%)$ was observed on treatment $\mathrm{MS}+1.0 \mathrm{mg} / \mathrm{l} \mathrm{BAP}+$ $1.0 \mathrm{mg} / \mathrm{l}$ kinetin $+200 \mathrm{mg} / \mathrm{l}$ activated charcoal. In vitro rooting of regenerated shoot was found in half strength MS medium supplemented with $0.5 \mathrm{mg} / \mathrm{l} \mathrm{NAA}+200 \mathrm{mg} / \mathrm{l}$ 
activated charcoal, which recorded the maximum number of root/ shoot (4.17) and root length $(3.87 \mathrm{~cm})$ (Desai et al., 2018). Reported the miropropagation protocol for pomegranate variety 'Bhagwa' using axillary buds as explants. The sterilization of explants was done using carbendazim-50\%, cefotaxime, kanamycin, streptocycline and mercuric chloride $(\mathrm{HgCl} 2)$. Among the twenty five different treatments tested for control of exudation, translocation of the explants five times at a regular interval of 24 $\mathrm{h}$ was effective. Two different media Murashige and Skoog (MS) and Woody Plant medium (WPM) were used for shoot induction. WPM supplemented with 1 mgl-16-benzylaminopurine (BAP) produced maximum number of $\operatorname{shoots}(5.17 \pm 1.23)$ among all the treatments tested for shoot induction. WPM supplemented with 1 mgl-1BAP also proved as the best treatment for multiple shoot induction and produced $11.21 \pm 0.14$ shoots. Treatment comprising of WP media supplemented with $5 \mathrm{mgl}-1$ cobalt chloride $(\mathrm{CoCl} 2)$ proved very effective in control of defoliation as the number of defoliated leaves $(3.60 \pm 0.86)$ and desiccated shoots $(0.60 \pm 0.24)$ recorded was very low. Highest number of roots $(5.60 \pm 0.74)$ and root length $(6.78 \pm 0.52 \mathrm{~cm})$ was obtained on WPM supplemented with 2000 mgl-1activated charcoal (AC). The plantlets with well-formed root systems were gradually acclimatized in greenhouse using cocopeat and later shifted to polyhouse (Kalalbandi et al., 2014). Shoot tip was found to be the best explant for culture establishment and there was effective control of microbial contamination when the plant was treatment with $0.1 \%$ mercuric chloride for $10 \mathrm{~min}$ and showed the maximum survival $(90.58 \%)$ and minimum microbial contamination $(9.52 \%)$. Maximum number of shoots per explant (1.73) was recorded in treatment $\mathrm{MS}+\mathrm{BAP}$ $2.0 \mathrm{mg} / \mathrm{l}$, while maximum shoot length and number of leaves were observed on medium containing MS + BAP $2.5 \mathrm{mg} / \mathrm{l}$. Half-strength MS medium along with NAA $8 \mathrm{mg} / \mathrm{l}$ gave the best rooting with maximum number of roots per shoot (4.00) and root length $(3.72 \mathrm{~cm})$. Hardening of rooted plantlets was ideal with maximum survival of plantlets $(71.72 \%)$ on medium containing soil + sand $(1: 1 ; \mathrm{v} / \mathrm{v})$ (Patil et al., 2011). Revealed that $1 \mathrm{mg} / \mathrm{l} \mathrm{MS+}$ Silver nitrate treatment recorded maximum number of shoot/explants, \% of explants showing response and shoot length in pomegranate.Success in commercially viable protocol for mass multiplication of plants using tissue culture begins with effective sterilization and reducing exudation from perennial fruit crops which makes the in vitro techniques more difficult (Patel et al., 2018). $\mathrm{He}$ also reported the explant sterilization with 300 mgl-1 bavistine (50\% carbendazim) for eighteen minutes, $200 \mathrm{mgl}-1$ each of streptocycline and cefotaxime for eighteen and eight minutes, respectively were found to be most the effective treatments to obtain cent per cent axenic culture development. Addition of activated charcoal $(0.25 \%)$ in media, significantly reduced the culture and explant browning (Bachake et al., 2019). Investigated micropropagation of pomegranate using shoot tips explant. The result reviled that combination of $\alpha$-Naphthalene acetic acid (NAA) and 6-Benzylaminopurine (BAP) was more responsive for culture establishment in modified MS + Adenine Sulphate $(60 \mathrm{mg} / \mathrm{l})+$ L-Arginine $(60 \mathrm{mg} / \mathrm{l})+1 \mathrm{mg} / \mathrm{l}$ Kinetin + $0.1 \mathrm{mg} / \mathrm{l} \mathrm{TDZ}+0.2 \mathrm{mg} / \mathrm{l} \mathrm{NAA}+$ Undisclosed media supplements) registered maximum proliferation rate (3.800), however, MS medium supplemented BAP + very low concentration of TDZ/ZR and adenine sulphate $(60 \mathrm{mg} / \mathrm{l})$ along with $0.1 / 0.2 \mathrm{mg}$ per litre NAA produced tallest shoot and high average shoot length. Major roots per shoot (5.00) and the rooting percent $(76 \%)$ were found highest in WPM medium supplemented with $1.0 \mathrm{mg} / \mathrm{l}$ NAA. Use of half strength concentration of MS medium and full strength 
WPM was an attempt to reduce the salt concentration to enhance rooting in vitro (Gorad et al., 2018).

Reported micropropagation protocol of $\mathrm{cv}$. Bhagwa. The study on surface sterilization revealed that explants treated with 0.1 percent mercuric chloride for 10 minutes showed the maximum survival percentage $(90.58 \%)$ and less contamination percentage (9.42) in shoot tip explants. Shoot differentiation study showed that maximum number of shots per shoot tip explant (1.73) containing MS + BAP $2.0 \mathrm{mg} / 1$, maximum shoot length $(2.80 \mathrm{~cm})$ was observed on medium containing MS + BAP $2.5 \mathrm{mg} / \mathrm{l}$ and maximum number of leaves (7.73) was recorded on medium containing $\mathrm{MS}+\mathrm{BAP} 2.5 \mathrm{mg} / \mathrm{l}$. Maximum number of roots (9.66) per shoot tip explant was recorded in treatment containing $1 / 2 \mathrm{MS}+$ NAA $6 \mathrm{mg} / \mathrm{l}$. Maximum root length on medium containing $1 / 2 \mathrm{MS}+\mathrm{IBA} \mathrm{mg} / \mathrm{l}$.

While hardening in different hardening media, it was observed that maximum $(71.87 \%)$ survival of plantlets from shoot tip explants was found on medium containing soil + sand $(1: 1 \mathrm{v} / \mathrm{v})$. Availability of healthy planting material is a foremost requirement for horticulture production, now a day's use of tissue culture technique are gaining popularity among pomegranate growers. But the use of tissue culture raised plant is still limited due to its higher cost.

Further there is need to develop or refinement of such protocol which reduces the cost of sapling also maintains the quality of tissue culture raised plant.

In conclusion, the exploitation of planting material which carries resistance or immunity against abiotic (temperature, drought and salinity) and biotic (disease especially bacterial blight, wilt and pest i.e. fruit borer) stress. Availability of such planting material with superior quality that ensure the economic security of growers. Micro propagation has great achievements in pomegranate propagation but need to furnish planting material on large scale either through government or private basis. The global market prefers the Indian pomegranate due to its quality production but need to boost on maximum extent and it happens only through successive propagation technique.

Need to conduct research on large scale for standardizing the best propagation method for maximum open field survival of sapling which can revolutionize the profitability and trust of nursery entrepreneurs and growers.

\section{References}

Abdul, H.S., Jaganath, M.K. Honnabyraiah, S. Mohan Kumar, S. Anil Kumar and Dayamani, K.J. 2018. Influence of Biofertilizer and Auxin on Growth and Rooting of Pomegranate (Punica granatum L.) Cuttings .International Journal of Current Microbiology and Applied Sciences 7 (2) 1187-1193.

Ahire, D. B. Ranpise, S. A. and Shete, M. B. 2017. Assessment of Graft Compatibility of Different Rootstocks of Pomegranate(Punica granatum L.). International Journal of Minor Fruits, Medicinal and Aromatic Plants. 3 (2): 2127.

Anonymous (2017). Indian Horticulture Database. National horticulture board, Ministry of Agriculture, Government of India, New Delhi.

Bachake, S.S, Jadhav, V.B., Deshpande, P.P., Tele, A.A., Banda, M.A., Adki, V.S., Gopika, M.K., Karanjule, P.G., Birajdar, S.B., Karwa, N.N., Mundhewadikar, D.M. and Singh, N.V. 2019. Standardization of in vitro propagation protocol for pomegranate cv. Super Bhagwa. Journal of Pharmacognosy and Phytochemistry, 8(3): 2548-2553.

Balestri, E., Vallerini, F., Castelli, A., Lardicci, C. 2012. Application of plant growth 
regulators, a simple technique for improving the establishment success of plant cuttings in coastal dune restoration. Estuarine, Coastal and Shelf Science. 99. 74-84.

Barde, P., Tiwari, R. Kanpure, R. N., Baghel, B. S. and Kumawat, B. R. 2010. Effect of biofertilizers and growth regulators on rooting and growth of pomegranate cuttings. Annals PI. Soil Res., 12 (1): 4647.

Bhatia, S., Sharma, K., Dahiya, R. and Bera, T. 2015. Modern Applications of Plant Biotechnology in Pharmaceutical Sciences. Micropropagation.361-368.

Bhosale, V.P., Jadav, R.G., Masu, M.M. 2009. Response of different medias and PGR's on rooting and survival of air layers in pomegranate (Punica granatum L.) cv. Sindhuri. The Asian J Horti. 4 (2):494-497

Blazkova, A., B. Sotta, H. Tranvan, R. Maldiney, M. Bonnet, J. Einhron, L. Kerhoas and E. Miginiac. 1997. Auxin metabolism and rooting in young and mature clones of Sequoia sempervirens. Physiol. Plant. 99:73-80.

Blazkova, A., B. Sotta, H. Tranvan, R. Maldiney, M. Bonnet, J. Eihorn, L. Kerhoas and E. Miginiac. 1997. Auxin metabolism and rooting in young and mature clones of Sequoia sempervirens. Physiol. Plant. 99:73-80.

Chandra, R, Babu, K.D. 2010. Propagation of pomegranate $-\mathrm{A}$ review. Fruit, Vegetable and Cereal and Biotechnology 4 (2): 51- 55.

Chandra, R. and Jadav, V.T. 2012. Grafting methods and time in pomegranate (Punica granatum) under semi-arid agro-climatic condition of Maharashtra. Indian Journal of Agricultural Sciences, 82 (11):990-992 .

Chandra, R., Jadhav, V.T., Sharma, J. and Marathe, R.A. 2011. Effect of grafting methods and time on scion sprouting, graft success and subsequent growth of grafted plants of pomegranate (Punica granatum L.)'Bhagawa'.Proc.II ${ }^{\text {nd }}$ IS on Pomegranate and Minor, including Mediterranean Fruits. Acta Hort. 890: 83-86.

Damar, D., Barholia, A. K., Lekhi, R. and Haldar, A. 2014. Effect of growth regulators and bio-fertilizers on survival of pomegranate
(Punica granatum L.) stem cuttings. Plant Archives, 14 (1):347-350.

Desai, P., Patil, G., Dholiya, B., Desai, S., Patel, F., \& Narayanan, S. 2018. Development of an efficient micropropagation protocol through axillary shoots proliferation for pomegranate variety 'Bhagwa'. Annals of Agrarian Science. 16:444-450

Diaz-Sal, C., Hutchison, K., Goldfarb, B. and Greenwood, M.S. 1996. Maturation-related loss of rooting competence by loblolly pine stem cuttings: the role of auxin transport, metabolism and tissue sensitivity. Physiol Plant 97:481-490.

Diaz-Sala, C., K.W. Hutchinson, B. Goldfarb and S. Greenwood. 1996. Maturation-related loss in rooting competence by loblolly pine stem cuttings: The role of auxin transport, metabolism and tissue sensitivity. Physiol. Plant. 97:481-490.

Eed, M.A., Bilal, A. and Almaqtari, S, 2015. The effect of growing media and stem cutting type on rooting and growth of Bougainvillea spectabilis plants.Univ. Aden J. Nat. and Appl. Sc. 19 (1): 141-146.

Elena, B., Vallerini, F., Alberto, C. and Claudio, L. 2012. Application of plant growth regulators, a simple technique for improving the establishment success of plant cuttings in coastal dune restoration. Estuarine, Coastal and Shelf Science. 99: 74-84.

Ghani, M., Sharma, M.K. and Habibi, H.K. 2019. Effect of Growing Media on Rhizogenesis and Growth of Rooted Stem Cuttings of Pomegranate (Punica granatum) cv. Phule Bhagwa Super. Under Open Field Condition, International Journal of Current Microbiology and Applied Sciences, 8 (7): 915-923.

Glick, B.R. 2012. Plant Growth-Promoting Bacteria: mechanisms and applications. Hindawi Publishing Corporation. Scientifica. (Cairo) 2012: 963401.

Gorad, D. S., Shaikh, S. A., Kallalbandi, B. M., Mali, A. S. 2018. In vitro propagation of pomegranate. International Journal of Advance Research, Ideas and Innovations in Technology.4 (4): 159-165.

Hore, J.K. and Sen, S.K. 1993. Root formation in pomegranate (Punica granatum L.) stem 
cutting with NAA and auxin synergists under intermittent mist. Crop Research, 6: 252-257.

Jain, P.K. and Parmar, K.L. 1993. Response in hardwood cuttings of pomegranate treated with rooting media, IBA and Boron. JNKVV Research Journal, 27(1): 56-58.

Kabir, M.A., Prince, M.H., Karim, R., Rahman, S., Billah, K.M.M., \& Hasnat, G.N.T. 2017. Vegetative Propagation of Punica granatum by Stem Cuttings Using NonMist Propagator, Int. J. Agr. Syst. 5(2): 185-197.

Kahramanoglu, I. and Umar, K. 2018. Effects of cutting length, time and growing media on the sprouting of dormant semi-hardwood cuttings of pomegranate cv. Wonderful. African Journal of Agricultural Research, 13(45), 2587-2590.

Kahramanoglu,I. and Umar, K. 2018 Effects of cutting length, time and growing media on the sprouting of dormant semi-hardwood cuttings of pomegranate cv. Wonderful, African Journal of Agricultural Research,13(45) : 2587-2590

Kalalbandi, B.M., Waskar, D.P., Khandare, V.S., Gorad, D.S.2014.Micropropagation studies on pomegranate var. Bhagwa, Indian Journal of Horticulture 71 (4) 564-566.

Karimi, H. R., BeniazN. and Mohammadi M.A. A. 2019. Effects of Rootstock on Growth Indices and Echo Physiological Parameters of Scion Pomegranate, International Journal of Fruit Science, 19, (3) 1-21.

Karimi, H.R. and Farahmand, H. 2011. Study of pomegranate (Punica granatum 1.) propagation using bench grafting, J. Fruit Ornam. Plant Res. vol. 19 (2) 2011: 67-72.

Karimi, H.R., Nowrozy, M. 2017. Effects of rootstock and scion on graft success and vegetative parameters of pomegranate, Scientia Horticulturae, 214: 280-287.

Kenney, G. Sudi, J. and Blackman, G.E. 1969. The uptake of growth substances XIII. Differential uptake of indole-3yl-acetic acid through the epidermal and cut surfaces of etiolated stem segments. J Exp Bot 20:820840.

Kour, R. (2009). Influence of season of planting on propagation of pomegranate. The Asian journal of Horticulture.4 (1): 253-254.
Kumar S., Patil P.B. and Patil C.P. 2001.Impact of inoculation on rootability of pomegranate cutting. Karnataka J. Agric. Sci. 14 (4): 1020-1024.

Madhuri, S.S. 2017. Recent advances in the production of pomegranate fruit crop, Agriculture UpdateVolume 12 | Issue 4 | November, 2017 | 657-665.

Materechera, S.A. and Seeiso, T.M. 2013. Seed treatment to improve water imbibition and germination of pomegranate (Punica granatum). Proc. $2^{\text {nd }}$ Int. Symp.on Underutilized Plants Species Crops for the Future - Beyond Food Security". Acta Hort. 979.

Mehta, S.K., Singh, K.K. and Singh, A. H. 2018. Effect of IBA concentration and time of planting on rooting in pomegranate (Punica granatum) cuttings, Journal of Medicinal Plants Studies, 6(1): 250-253.

Mehta, S.K., Singh, K.K., Harsana, A.S. 2018. Effect of IBA concentration and time of planting on rooting in pomegranate (Punica granatum) cuttings. Journal of Medicinal Plants Studies 6 (1):250-253.

Melgarejo, P., Martinez, J., Martinez, J.J. and Sanchez, M. 2000. Study of the rooting capacity of eleven pomegranate (Punica granatum L.) clones, using plastic to cover the soil. Advances in research and technology. 42: 169-173.

Murkute A.A., Patil S. and Singh S.K. 2004. In vitro regeneration in pomegranate $\mathrm{cv}$. Ganesh from mature trees. Indian $\mathrm{j}$. hort. 61(3): 206-208.

Naik, S,K., Pattnaik, S. and Chand, P.K. 1999. In vitro propagation of pomegranate (Punica granatum L. cv. Ganesh) through axillary shoot proliferation from nodal segments of mature tree. Sci Hortic 79:175-183.

Navjot and Kahlon,P.S. 2007. Studies on the propagation of pomegranate as influenced by season and shoot portion, The Asian Journal of Horticulture, 2 (1): 6-8.

Olmez, Z. Temel F., Gokturk S. and Yahyaoglu Z. 2007.Effects of Sulphuric Acid and Cold Stratification Pretreatments on Germination of Pomegranate (Punica granatum L.)Seeds. Asian Journal of Plant Sciences. 6 (2): 427-430.

OuYang, F., Wang, J. \& Li, Y. 2015. Effects of 
cutting size and exogenous hormone treatment on rooting of shoot cuttings in Norway spruce [Picea abies (L.) Karst.]. New Forests 46, 91-105.

Owais, S.J. 2010. Rooting response of five pomegranate varieties toIndole Butyric Acid concentration and cuttings age. Pakistan Journal of Biological Sciences 13 (2): 51-58.

Panda, C.M. 2014. Studies on propagation method of pomegranate (Punica granatum 1.) by cutting in coastal climate of odisha. Unpabulish Master Thesis, Orissa University of Agriculture and Technology, Bhubaneswar, Orrisa,

Patel, A., Patil G., Mankad, M. and Subhash, N. 2018. Optimization of surface sterilization and manipulation of in vitro conditions for reduced browning in pomegranate (Punicagranatum L.) variety Bhagava, International Journal of Chemical Studies. 6(3): 23-28.

Patel, D.M., Nehete, D.S., Jadav, R.G. and Satodiya, B.N. 2012. Effect of PGR's and rooting media on air layering of different pomegranate (Punica granatum L.) cultivars. The Asian Journal Of Horticulture, 7(1):89-93.

Patil, V.M., Dhande, G.A., Dipak, M.T. and Rajpu, J.C. 2011. Micropropagation of pomegranate

(Punica granatumL.)'Bhagava' cultivar from nodal explants. African Journal of Biotechnology.10 (79): 18130-18136.

Purohit, A.G. and Shekarappa, K.E. 1985. Effect of type of cutting and indolebutyric acid on rooting of hardwood cuttings of pomegranate (Punica granatum L). Indian J. Horticulture, 42: 30-36.

Rajan, S. Markose, B.L. 2007. Propagation of horticultural crops. In: Peter KV (Ed) Horticulture Science Series, New India Publishing Agency, New Delhi, India 6:8484.

Rajkumar, R., Gora, J. S., Kumar, R., Singh, A., Kumar, A., \& Gajender, G. 2017. Effect of different growing media on the rooting of pomegranate (Punica granatum L.) cv. 'Phulearakta' cuttings. Journal of Applied and Natural Science, 9(2), 715-719.

Ram, R.B., Kumar, P. and Kumar, A. 2005.Effect of IBA and PHB on regeneration of pomegranate (Punica granatum L.) through stem cuttings. New Agriculturist.16 $(1,2)$ : 113-122.

Ranpise, S. A. and Ahire, D. B. 2016. Effect of different grafting methods and rootstocks on growth and survival ofpomegranate (Punica granatum L.) IJMFM\&AP 2 (2): 22-28.

Saroj, P.L., Awasthi, O.P., Bhargava, R. and Singh, U.V. 2008. Standardization of pomegranate propagation by cutting under mist system in hot arid region. Indian J. Horticulture, 65: 25-30.

Sharma, N., Anand, R. and Dharminder, K. 2009. Standardization of pomegranate (Punica garanatum L.) propagation through cuttings. Biological Forum-An International Journal. 1 (1): 2136-80.

Shinde, B. N. 2012. Effect of IBA and rooting media on growth of pomegranate cuttings (Punica granatum L), Unpabulish Master Thesis. Vasantrao Naik Marathwada Krishi Vidyapeeth, Parbhani. Pp-115.

Singh, B., Singh, S. and Singh, G. 2011. Influence of planting time and IBA on rooting and growth of pomegranate (Punica granatum 1.) 'ganesh' cuttings. Acta Hortic. 890, 183-188.

Singh, K. K. 2017. Vegetative Propagation of Pomegranate (Punica granatum L.) through Cutting- A Review. Int.J.Curr.Microbiol.App.Sci. 6 (10): 48874893.

Singh, P., Patel, R.M. and Kadam, S. (2013). In vitro mass multiplication of pomegranate from cotyledonary nodal explants $\mathrm{cv}$. Ganesh. African J. Biotechnol., 12 (20): 2863-2868.

Singh, N.V. Chandra, Ram, Awachare, C.M., Bab u K.D. and Pal, R.K (2017). A novel method of propagation in pomegranate: Mound layering, Progressive Horticulture 49 (1) pp 92-94

Sonawane, M, S. 2017. Recent advances in the production of pomegranate fruit crop. Agric. Update, 12 (4): 657-665.

Taheri, M.S.,Gholami, M., Baninasab ,B., Mostafa,M. and Moradi,S. 2014. Pomegranate seed germination and dormancy breaking techniques. Seed 
Technology. 36 (2) : 139-149.

Tanuja, M. Rana, D. K. and Naithani, D.C. 2017. Effect of different growing media on vegetative growth and rooting in pomegranate (Punica granatum 1.) cv. "kandhari" hardwood stem cutting under mist Plant Archives, 17 (1) 2017 pp. 391394.

Tayade, SA, Joshi PS, Dahapute VM and Nagre PK. 2018. Response of number of air layers per shoot in pomegranate cv. Bhagwa. International Journal of Chemical Studies. 6(2): 1610-1613.

Tiberia, P., Doru, P. and Catherine, B. 2011. Auxin Control in the Formation of Adventitious Roots. Notulae Botanicae Horti Agrobotanici Cluj-Napoca. 39. 307316.

Tomar, K.S. 2011.Effect of different concentrations of growth regulators on rooting and survival percentage of pomegranate air layers. Prog. Agric. 11(2):431-433.

Tripathi, S.N. and Shukla, H.S. 2004. Propagation of pomegranate (Punica granatum L.) cultivars by stem cutting with indole butyric acid and p-hydroxybenzoic acid. Indian Journal of Horticulture, 61(4): 362365 .

Vazifeshenas, M., Khayyat, M., Salma, J. and Samadzadeh, A. 2009. Effects of different scion-rootstock combinations on vigor, tree size, yield and fruit quality of three Iranian cultivars of pomegranate, Fruits, 64 (6): 343-349.

\section{How to cite this article:}

Pawar. Y. D. and Pushpraj Singh. 2020. Advances in Propagation Techniques of Pomegranate. Int.J.Curr.Microbiol.App.Sci. 9(06): 2122-2137. doi: https://doi.org/10.20546/ijcmas.2020.906.260 